\title{
Statin use in primary inflammatory breast cancer: a cohort study
}

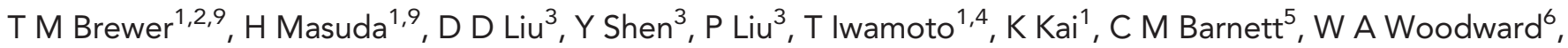 \\ J M Reuben ${ }^{7}$, P Yang $^{8}$, G N Hortobagyi ${ }^{1}$ and N T Ueno ${ }^{*}, 1$ \\ ${ }^{1}$ Morgan Welch Inflammatory Breast Cancer Research Program and Clinic, Department of Breast Medical Oncology, The \\ University of Texas MD Anderson Cancer Center, Houston, TX 77030, USA; ${ }^{2}$ School of Medicine, Eastern Virginia Medical School, \\ Norfolk, VA 23501, USA; ${ }^{3}$ Department of Biostatistics, The University of Texas MD Anderson Cancer Center, Houston, TX 77030, \\ USA; ${ }^{4}$ Department of Breast and Endocrine Surgery, Okayama University Hospital, Okayama 700-0082 Japan; ${ }^{5}$ Division of \\ Pharmacy, The University of Texas MD Anderson Cancer Center, Houston, TX 77030, USA; ${ }^{6}$ Department of Radiation Oncology, \\ The University of Texas MD Anderson Cancer Center, Houston, TX 77030, USA; ${ }^{7}$ Department of Hematopathology, The University \\ of Texas MD Anderson Cancer Center, Houston, TX 77030, USA and ${ }^{8}$ Department of General Oncology, The University of Texas \\ MD Anderson Cancer Center, Houston, TX 77030, USA
}

Background: Some studies have suggested that statins, which have cholesterol-lowering and anti-inflammatory properties, may have antitumor effects. Effects of statins on inflammatory breast cancer (IBC) have never been studied.

Methods: We reviewed 723 patients diagnosed with primary IBC in 1995-2011 and treated at The University of Texas MD Anderson Cancer Center. Statin users were defined as being on statins at the initial evaluation. Based on Ahern et al's statin classification (J NCl, 2011), clinical outcomes were compared by statin use and type (weakly lipophilic to hydrophilic (H-statin) vs lipophilic statins (L-statin)). We used the Kaplan-Meier method to estimate the median progression-free survival (PFS), overall survival (OS) and disease-specific survival (DSS), and a Cox proportional hazards regression model to test the statistical significance of potential prognostic factors.

Results: In the multivariable Cox model, H-statins were associated with significantly improved PFS compared with no statin (hazard ratio $=0.49 ; 95 \%$ confidence interval $=0.28-0.84 ; P<0.01$ ); OS and DSS $P$-values were 0.80 and 0.85 , respectively. For L-statins vs no statin, P-values for PFS, DSS, and OS were $0.81,0.4$, and 0.74 , respectively.

Conclusion: $\mathrm{H}$-statins were associated with significantly improved PFS. A prospective randomised study evaluating the survival benefits of statins in primary IBC is warranted.

Inflammatory breast cancer (IBC) is rare, comprising only $2-5 \%$ of breast cancer incidences, but is the most lethal type of breast cancer, representing $8-10 \%$ of breast cancer mortality (Keeneth et al, 2005). Clinically, IBC presents with apparent inflammatory changes of the breast, characterised by diffuse erythema and oedema of the skin with or without an underlying palpable mass. The diagnosis is pathologically confirmed by recognising invasive carcinoma in a core biopsy specimen (Dawood et al, 2011). Although patients with primary IBC have no evidence of distant metastases at the time of diagnosis, the disease tends to have rapid progression from onset, higher risk of recurrence, and shortened survival compared with locally advanced non-IBC (Cristofanilli et al, 2007). Despite advances in breast cancer treatment and a multidisciplinary approach (introduced at MD Anderson Cancer

\footnotetext{
*Correspondence: Professor NT Ueno; E-mail: nueno@mdanderson.org

San Antonio Breast Cancer Symposium, San Antonio, TX, 4-8 December 2012 (poster discussion).

${ }^{9} \mathrm{TM}$ Brewer and $\mathrm{H}$ Masuda contributed equally to this work.
}

Received 4 March 2013; revised 31 May 2013; accepted 11 June 2013; published online 2 July 2013 
Center in 1974), patients with IBC continue to have poor prognosis (Gonzalez-Angulo et al, 2007). The biological mechanism responsible for the aggressive nature of primary IBC is not yet fully understood. Although calling this type of breast cancer 'inflammatory' implies the existence of an underlying inflammatory mechanism, the term is a clinical description reflecting redness of the skin and does not denote the presence of an obvious pathologic inflammatory infiltrate in these tumours.

Statins, 3-hydroxyl-3-methylglutaryl coenzyme A (HMG$\mathrm{CoA}$ ) reductase inhibitors, are cholesterol-lowering agents that significantly reduce cardiovascular events and overall mortality; they are also recognised as powerful anti-inflammatory agents Lefer (2002). Statin use substantially increased between the periods of 1988 and 1994 and 2005 and 2008, with a 10-fold increase in use by people aged 45 years and older (Ma et al, 2005; National Center for Health Statistics (US), 2010). Interestingly, multiple preclinical studies have demonstrated that statins possess tumour-suppressive effects and reduce metastatic potentials in breast cancer animal models and cell lines (Rao et al, 1998; Shibata et al, 2004; Ghosh-Choudhury et al, 2010; Mandal et al, 2011). HMG-CoA reductase has a crucial role in the regulation of the mevalonate pathway, which has been shown to contribute to tumour aetiology. Dysregulation of the mevalonate pathway was found to upregulate ectopic HMG-CoA reductase expression and to promote colony formation and tumour growth in breast cancer cells in vivo (Clendening et al, 2010). Increased mevalonate synthesis promoted tumour proliferation in a mouse breast cancer model (Duncan et al, 2004). Furthermore, in a metaanalysis of 865 breast cancer patients from six microarray data sets, high HMG-CoA reductase mRNA levels were found correlated with poor survival outcomes (Clendening et al, 2010). A review by Konstantinopoulos et al (2007) mentions, among several possible antitumor mechanisms of statins, the importance of post-translational modifications. Statins inhibit production of isoprenoids, which are one of the important products of the mevalonate pathway and substrates for geranylgeranylation, a type of post-translational modification that adds the geranylgeranyl isoprene unit to the target protein, such as RHO proteins, thus inhibiting carcinogenesis (Konstantinopoulos et al, 2007).

Some evidence from the bedside supports these proposed mechanisms. One study showed that post-diagnostic statin use decreased the risk of breast cancer recurrence (Kwan et al, 2008). A large Danish study showed that use of simvastatin, a highly lipophilic statin, reduced recurrence risk by 10 fewer cases per 100 women over 10 years among Danish women with Stage I-III breast cancer (Ahern et al, 2011). In the same study, Ahern et al (2011) showed the simvastatin group had 30\% reduction in recurrence over 10 years (hazard ratio $(\mathrm{HR})=0.70 ; 95 \%$ confidence interval $(\mathrm{CI})=0.57-0.8)$. Nielsen et al (2012) reported that statin use was associated with reduced cancer-related death in a large Danish study that included over 295000 cancer patients. Interestingly, pravastatin, a hydrophilic statin, was associated with a statistically significant increase in breast cancer incidence in the CARE trial (Sacks et al, 1996). Additionally, a large prospective study by Cauley et al (2006) involving 156351 healthy women showed that lipophilic statins (simvastatin, lovastatin, and fluvastatin) were associated with lower incidence of invasive breast cancer, suggesting that certain statins may contribute to the primary prevention of breast cancer.

Overall results of multiple epidemiologic studies on the effects of statin use on breast cancer risks, however, are inconclusive with the majority finding no clear association (Bonovas et al, 2005). As noted by Prowell et al (2006), many of the observational studies, which have analysed findings for all statin users as a single group, may have failed to reveal protective effects of certain types of statins. Studies comparing outcomes for different types of statins could reveal antitumor effects of a subset.
To the best of our knowledge, no study has examined the association between statin use and survival outcomes in primary IBC. We hypothesised that statins, particularly lipophilic statins, reduce the recurrence potential of primary IBC. The main purpose of this observational study was to determine whether statin use affected the recurrence rate and survival in patients with primary IBC who were treated at The University of Texas MD Anderson Cancer Center from 1995 to 2011. We also examined other known prognostic variables and the types of statins used to determine their effects on clinical outcomes.

\section{PATIENTS AND METHODS}

Patients. We searched the Inflammatory Breast Cancer Database compiled by the Breast Cancer Management System at MD Anderson Cancer Center, which contains 1177 entries of patients diagnosed with all stages of IBC between 24 February 1970 and 27 January 2011. The following exclusion criteria were applied: IBC diagnosed before 1995, stage IV disease, secondary IBC, suspected non-IBC breast cancer, unknown clinical stage, statin use after the initial evaluation at MD Anderson, unclear statin type, and notation of 'restricted information' in MD Anderson's electronic medical record (EMR) system. Patients with unknown timing of statin use and who were not apparent statin users according to the History and Physical section of the EMR were excluded to avoid the confounding effect of statin and adjuvant treatment. We defined secondary IBC as any IBC that occurred after presentation with a non-IBC breast cancer or IBC noted as 'secondary IBC' in the EMR. After 454 entries were eliminated under these criteria, a total of 723 patients were included in our study cohort.

Data for age, menopausal status, body mass index (BMI), race, clinical stage, nuclear grade and oestrogen receptor (ER), and progesterone (PR) status were directly extracted from the database. ER status and PR status had been determined with immunohistochemistry (IHC) with a cutoff of $10 \%$ for positivity. HER2 status was considered negative if (a) IHC results were 0 to +1 without FISH results or (b) FISH results were negative. HER2 status was considered positive if (a) IHC results were +3 without FISH results or (b) FISH results were positive (regardless of IHC results). Lymphatic/vascular invasion was determined to be present if both lymphatic and vascular invasions were recorded as positive in the database.

From the History and Physical section of the EMR, we collected information on statin use, types of statins used, comorbidities (namely hypertension and diabetes mellitus), and medications other than statins, which could affect survival and relapse outcomes (namely insulin, metformin, angiotensin-converting enzyme inhibitors (ACEIs), angiotensin receptor blockers (ARBs), and bisphosphonates).

Statin users were defined as those whose records indicated statin use at the time of the initial evaluation at MD Anderson Cancer Center, documented in the History and Physical section of the EMR. Patients who were exclusively prescribed lipophilic statins (simvastatin, fluvastatin, and lovastatin) were classified as the lipophilic statin (L-statin) group, whereas those prescribed weakly lipophilic to hydrophilic statins (atorvastatin, pravastatin, and rosuvastatin) were classified as the hydrophilic statin (H-statin) group. The hydrophobicity classification of statins, shown in Table 1, was extracted from the large Danish study by Ahern et al (2011).

In the analysis based on statin types, patients who used both drug categories or without information on statin types were excluded. We further extracted patients on either simvastatin or atorvastatin and each group was compared with non-statin users. Sixteen patients using other types of statins were excluded from the data. Twenty-nine L-statin users and $44 \mathrm{H}$-statin users were included in the sub-analyses. 
The MDA Institutional Review Board approved the protocol for this study and granted a waiver of informed consent based on the observational nature of the study.

Outcomes. The primary outcome of this study was progressionfree survival (PFS), the time in years between the diagnosis date and recurrence, progression or death. Secondary outcomes included overall survival (OS), the time interval in years from the diagnosis date to the date of death due to all causes or the last follow-up date, and disease-specific survival (DSS), the time in years from the diagnosis date to date of death due to breast cancer. For the DSS calculation, only patients whose outcomes were recorded as 'dead with disease' were considered to have had positive events and others were censored at the time of their death or at their last follow-up dates.

Statistical analysis. The variables of interest include age, race, BMI, diabetes, and its treatments (insulin and metformin), hypertension and its treatments (ACEIs, ARBs, and beta blockers), bisphosphonate use, clinical stage, menopausal status, nuclear grade, lymphatic invasion, vascular invasion, neoadjuvant therapy, adjuvant therapy, radiation therapy, and definitive surgery within 1 year. Data were first summarised using standard descriptive statistics and frequency tabulation. Associations between categorical variables were assessed via cross-tabulation and the $\chi^{2}$-test or Fisher's exact test, whichever was appropriate. Survival distributions for PFS, OS, and DSS were estimated using the Kaplan-Meier method (Kaplan and Meier, 1958). Both univariate and multicovariate Cox proportional hazard models were applied to assess the effect of covariates of interest on PFS and OS (Cox, 1958). We obtained the final multivariate models by keeping the covariates that were significant in the univariate models first and using a backward selection approach, removing the least significant covariate from the full model one at a time. A $P$-value of $<0.05$ was used as the limit for inclusion. Radiation therapy, HER2 status and ER/PR status were treated as stratification factors in the multivariate Cox modes because they did not satisfy the proportional hazards assumption. Age, either continuous or dichotomous, was not statistically significant to predict the survival outcomes and thus was not included in the multivariate models. All computations were carried out using SAS 9.3 (SAS Institute Inc., Cary, NC, USA) and S-PLUS 8.2 software (Tibco Software Inc., Palo Alto, CA, USA).

\section{RESULTS}

Patient demographics and clinical characteristics. We analysed 723 women with stage III disease (primary IBC) diagnosed between 12 January 1995 and 27 January 2011. Among these, 73 were statin users at the time of the initial evaluation and 650 were not. Given that the types of statin may influence survival outcomes, the statin users were further divided into lipophilic (L-statin, $n=29$ ) and weakly lipophilic to hydrophilic (H-statin, $n=44)$ statin groups according to the classification used by Ahern et al (2011) (Table 1). Table 2 shows the number and percentage of statin users of our cohort by statin type.

The mean age of statin users tended to be older (H-statin users 58.8 years, range 39.1 to 75.4 ; L-statin users 58.9 years, range 27.6-75.4 years; nonusers 48.9 years, range 22.7-87.7 years; $P<0.01)$, and thus a higher proportion of statin users had postmenopausal status $(P<0.01)$. Furthermore, statin users had more comorbidities, including hypertension $(P<0.01)$ and diabetes $(P<0.01)$. Insulin, metformin, beta-blocker, and ACEI/ARB use was more frequent among statin users $(P<0.01)$. The L-statin group was less likely to receive adjuvant chemotherapy than $\mathrm{H}$-statin users $(P<0.01)$. Other patient characteristics, namely ER status, PR status, HER2 status, triple-negative status, nuclear grade,
Table 1. Statin classification based on the log partition coefficient, adopted from a Danish nationwide prospective cohort study conducted by Ahern et al (2011)

\begin{tabular}{|l|c|c|c|}
\hline $\begin{array}{l}\text { Solubility } \\
\text { classification }\end{array}$ & $\begin{array}{c}\text { Drug } \\
\text { name }\end{array}$ & $\begin{array}{c}\text { Anatomical } \\
\text { therapeutic } \\
\text { chemical code }\end{array}$ & $\begin{array}{c}\text { Log partition } \\
\text { coefficient } \\
\text { (octanol:water) }\end{array}$ \\
\hline Lipophilic & Simvastatin & C10AA01 & 4.7 \\
\hline & Lovastatin & C10AA02 & 4.3 \\
\hline & Fluvastatin & C10AA04 & 3.5 \\
\hline Hydrophilic & Cerivastatin & C10AA06 & 3.6 \\
\hline & Atorvastatin & C10AA05 & 1.5 \\
\hline & Rosuvastatin & C10AA07 & 1.6 \\
\hline $\begin{array}{l}\text { Reproduced with kind permission of Oxford University Press from Ahern et al (2011). } \\
\text { a Partition coefficient for atorvastatin and pravastatin were reported by Kubota et al (2004). } \\
\text { Remaining partition } \\
\text { Biotechnology Information Pub Chem database (http://pubchem.ncbi.nlm.hih.gov/). }\end{array}$ \\
\hline
\end{tabular}

Table 2. Frequency and percentage of statin users by statin type

\begin{tabular}{|l|l|c|}
\hline Groups & Statin name & $\mathbf{N}(\%)$ \\
\hline L-statin & Fluvastatin & $1(3.4 \%)$ \\
\hline & Lovastatin & $1(3.4 \%)$ \\
\hline $\mathrm{H}$-statin & Simvastatin & $27(93.1 \%)$ \\
\hline & Atorvastatin & $29(65.9 \%)$ \\
\hline & Pravastatin & $9(20.5 \%)$ \\
\hline & Pravastatin and rosuvastatin & $1(2.3 \%)$ \\
\hline & Rosuvastatin & $5(11.4 \%)$ \\
\hline
\end{tabular}

Abbreviations: L-statin = lipophilic statin; $\mathrm{H}$-statin = hydrophilic to weakly lipophilic statin The classification of statins is from Ahern et al (2011), as shown in Table 1.

lymphatic/vascular invasion, race, bisphosphonate use, and receipt of neoadjuvant chemotherapy and radiation therapy were well balanced between the three groups. Table 3 summarises the baseline patient characteristics of our cohort.

Survival estimates. With a median follow-up of 2.9 years, 366 patients died, of which 338 died of breast cancer. Of 652 stage III IBC patients who had follow-up data for disease progression, 433 had progressive disease or died (PD/death). The median PFS time was 1.8 years $(95 \% \mathrm{CI}=1.7-2.1)$. The $2-, 5-$, and 10 -year PFS rates (95\% CI) were $47.4 \%(43.5-51.6 \%), 26.8 \%(23.1-31.1 \%)$, and $18.6 \%(14.7-23.7 \%)$, respectively. The factors that were statistically significant in predicting longer time to progression/death in the univariate analysis were higher BMI, statin use, lower nuclear grade, negative lymphatic, and vascular involvement, positive ER status, positive PR status, negative triple-negative status, bisphosphonate use, adjuvant hormonal therapy, and radiotherapy. The group taking any type of statin had a significantly lower recurrence risk ( $\mathrm{HR}(95 \% \mathrm{CI})=0.63(0.42-0.96), P=<0.01)$ than did the group taking no statins. In this analysis, the HRs for OS and DSS were $1.00(P=0.99)$ and $0.95 \quad(P=0.83)$, respectively (Supplementary table). The median PFS times were significantly different among the statin user groups: 4.9 years, 2.5 years, and 1.8 years $(P=0.04)$ for patients who took $\mathrm{H}$-statins, L-statins, and no statin, respectively. The median OS times were 5.1 years, 3.8 years, and 4.3 years $(P=0.35)$ and the median DSS times 5.1 years, 3.8 years, and 4.5 years $(P=0.37)$ for the H-statin, L-statin, and non-statin groups, respectively. 


\begin{tabular}{|c|c|c|c|c|c|}
\hline Covariate & Levels & No statin & L-statin & H-statin & $\boldsymbol{P}$-value \\
\hline \multirow[t]{2}{*}{ Age } & $<50$ & $359(55.2 \%)$ & 5 (17.2\%) & $6(13.6 \%)$ & $<0.01$ \\
\hline & $\geqslant 50$ & $291(44.8 \%)$ & $24(82.8 \%)$ & $38(86.4 \%)$ & \\
\hline \multirow[t]{3}{*}{ Race } & White & $562(86.5 \%)$ & 26 (89.7\%) & 41 (93.2\%) & 0.71 \\
\hline & Black & $63(9.7 \%)$ & 3 (10.3\%) & $3(6.8 \%)$ & \\
\hline & Other & 25 (3.8\%) & 0 & 0 & \\
\hline \multirow[t]{3}{*}{ BMI } & $<25$ & $162(26.5 \%)$ & $6(25 \%)$ & $4(10 \%)$ & 0.07 \\
\hline & $\geqslant 25$ and $<30$ & 199 (32.5\%) & 5 (20.8\%) & $13(32.5 \%)$ & \\
\hline & $\geqslant 30$ & $251(41 \%)$ & $13(54.2 \%)$ & $23(57.5 \%)$ & \\
\hline \multirow[t]{2}{*}{ Menopausal status } & Post & 313 (48.6\%) & $24(82.8 \%)$ & $38(88.4 \%)$ & $<0.01$ \\
\hline & Pre & 331 (51.4\%) & $5(17.2 \%)$ & $5(11.6 \%)$ & \\
\hline \multirow[t]{2}{*}{ ER } & Negative & 334 (56.1\%) & $17(60.7 \%)$ & $20(50 \%)$ & 0.66 \\
\hline & Positive & $261(43.9 \%)$ & 11 (39.3\%) & $20(50 \%)$ & \\
\hline \multirow[t]{2}{*}{ PR } & Negative & $394(67.4 \%)$ & 22 (81.5\%) & $26(65 \%)$ & 0.28 \\
\hline & Positive & $191(32.6 \%)$ & 5 (18.5\%) & $14(35 \%)$ & \\
\hline \multirow[t]{2}{*}{$\mathrm{HR}$} & Negative & 304 (51.2\%) & $16(57.1 \%)$ & $16(40 \%)$ & 0.31 \\
\hline & Positive & $290(48.8 \%)$ & 12 (42.9\%) & $24(60 \%)$ & \\
\hline \multirow[t]{2}{*}{ HER2 } & Negative & $316(61.4 \%)$ & 19 (79.2\%) & 27 (71.1\%) & 0.12 \\
\hline & Positive & 199 (38.6\%) & $5(20.8 \%)$ & $11(28.9 \%)$ & \\
\hline \multirow[t]{2}{*}{ TNBC } & Non-TNBC & $420(75.3 \%)$ & $16(64 \%)$ & $28(71.8 \%)$ & 0.41 \\
\hline & TNBC & $138(24.7 \%)$ & $9(36 \%)$ & $11(28.2 \%)$ & \\
\hline \multirow[t]{3}{*}{ Nuclear grade } & 1 & $6(1 \%)$ & 0 & 0 & 0.18 \\
\hline & II & 102 (17.4\%) & $8(29.6 \%)$ & $12(29.3 \%)$ & \\
\hline & III & 478 (81.6\%) & $19(70.4 \%)$ & $29(70.7 \%)$ & \\
\hline \multirow[t]{2}{*}{ Lymphatic invasion } & Negative & 209 (35.9\%) & $11(42.3 \%)$ & $19(46.3 \%)$ & 0.34 \\
\hline & Positive & $373(64.1 \%)$ & 15 (57.7\%) & $22(53.7 \%)$ & \\
\hline \multirow[t]{2}{*}{ Vascular invasion } & Negative & $268(46.2 \%)$ & $11(42.3 \%)$ & $20(50 \%)$ & 0.82 \\
\hline & Positive & 312 (53.8\%) & $15(57.7 \%)$ & $20(50 \%)$ & \\
\hline \multirow[t]{2}{*}{ Lymphatic/vascular invasion } & Either negative & $277(47.8 \%)$ & $11(42.3 \%)$ & $20(50 \%)$ & 0.82 \\
\hline & Positive/positive & 302 (52.2\%) & 15 (57.7\%) & $20(50 \%)$ & \\
\hline \multirow[t]{2}{*}{ Neoadjuvant chemotherapy } & No & $52(8 \%)$ & 0 & $3(6.8 \%)$ & 0.32 \\
\hline & Yes & $598(92 \%)$ & $29(100 \%)$ & $41(93.2 \%)$ & \\
\hline \multirow[t]{2}{*}{ Neoadjuvant hormonal therapy } & No & $636(97.8 \%)$ & $29(100 \%)$ & $44(100 \%)$ & 1.00 \\
\hline & Yes & $14(2.2 \%)$ & 0 & 0 & \\
\hline \multirow[t]{2}{*}{ Adjuvant chemotherapy } & No & $343(52.8 \%)$ & 25 (86.2\%) & $25(56.8 \%)$ & $<0.01$ \\
\hline & Yes & 307 (47.2\%) & $4(13.8 \%)$ & $19(43.2 \%)$ & \\
\hline \multirow[t]{2}{*}{ Adjuvant hormonal therapy } & No & $449(69.1 \%)$ & $21(72.4 \%)$ & $25(56.8 \%)$ & 0.21 \\
\hline & Yes & $201(30.9 \%)$ & $8(27.6 \%)$ & $19(43.2 \%)$ & \\
\hline \multirow[t]{2}{*}{ Radiation therapy } & No & $165(25.4 \%)$ & $6(20.7 \%)$ & $11(25 \%)$ & 0.85 \\
\hline & Yes & 485 (74.6\%) & $23(79.3 \%)$ & $33(75 \%)$ & \\
\hline Diabetes mellitus & No & $601(92.5 \%)$ & 20 (69\%) & $29(65.9 \%)$ & $<0.01$ \\
\hline & Yes & 49 (7.5\%) & 9 (31\%) & $15(34.1 \%)$ & \\
\hline Insulin & No & 637 (98\%) & $25(86.2 \%)$ & 40 (90.9\%) & $<0.01$ \\
\hline & Yes & $13(2 \%)$ & 4 (13.8\%) & $4(9.1 \%)$ & \\
\hline Metformin & No & $627(96.5 \%)$ & $24(82.8 \%)$ & $36(81.8 \%)$ & $<0.01$ \\
\hline & Yes & $23(3.5 \%)$ & $5(17.2 \%)$ & $8(18.2 \%)$ & \\
\hline Hypertension & No & $520(80 \%)$ & $9(31 \%)$ & $19(43.2 \%)$ & $<0.01$ \\
\hline & Yes & $130(20 \%)$ & $20(69 \%)$ & $25(56.8 \%)$ & \\
\hline ACEI or ARB & No & $562(86.5 \%)$ & $16(55.2 \%)$ & $23(52.3 \%)$ & $<0.01$ \\
\hline & Yes & $88(13.5 \%)$ & $13(44.8 \%)$ & $21(47.7 \%)$ & \\
\hline Beta-blocker & No & $568(87.4 \%)$ & $17(58.6 \%)$ & $26(59.1 \%)$ & $<0.01$ \\
\hline & Yes & $82(12.6 \%)$ & $12(41.4 \%)$ & $18(40.9 \%)$ & \\
\hline Bisphosphonate & No & $606(93.2 \%)$ & 24 (82.8\%) & 42 (95.5\%) & 0.09 \\
\hline & Yes & $44(6.8 \%)$ & 5 (17.2\%) & 2 (4.5\%) & \\
\hline Surgery within 1 year & No & 77 (11.8\%) & 2 (6.9\%) & 5 (11.4\%) & 0.84 \\
\hline & Yes & $573(88.2 \%)$ & $27(93.1 \%)$ & $39(88.6 \%)$ & \\
\hline
\end{tabular}


Table 4. Univariate and multicovariate cox model for PFS, OS, and DSS for $\mathrm{H}$-statin and L-statin when compared with non-statin users

\begin{tabular}{|c|c|c|c|c|}
\hline & \multicolumn{2}{|c|}{ Univariate cox model } & \multicolumn{2}{|c|}{$\begin{array}{c}\text { Multicovariate cox } \\
\text { model }\end{array}$} \\
\hline Covariates & $\mathrm{HR}(95 \% \mathrm{Cl})$ & $\boldsymbol{P}$-value & HR (95\% Cl) & $\boldsymbol{P}$-value \\
\hline \multicolumn{5}{|l|}{ PFS } \\
\hline $\begin{array}{l}\text { Statin } L \text { vs N } \\
H \text { vs } N\end{array}$ & $\begin{array}{l}0.94(0.57-1.55) \\
0.55(0.35-0.87)\end{array}$ & $\begin{array}{l}0.81 \\
0.01\end{array}$ & $\begin{array}{l}0.76(0.41-1.41) \\
0.49(0.28-0.84)\end{array}$ & $\begin{array}{r}0.38 \\
<0.01\end{array}$ \\
\hline \multicolumn{5}{|l|}{ os } \\
\hline $\begin{array}{l}\text { Statin } L \text { vs } N \\
H \text { vs } N\end{array}$ & $\begin{array}{l}1.23(0.71-2.15) \\
0.75(0.46-1.20)\end{array}$ & $\begin{array}{l}0.46 \\
0.23\end{array}$ & $\begin{array}{l}1.46(0.73-2.90) \\
0.80(0.43-1.49)\end{array}$ & $\begin{array}{l}0.28 \\
0.49\end{array}$ \\
\hline \multicolumn{5}{|l|}{ DSS } \\
\hline $\begin{array}{l}\text { Statin } L \text { vs N } \\
H \text { vs } N\end{array}$ & $\begin{array}{l}1.11(0.61-2.03) \\
0.71(0.43-1.17)\end{array}$ & $\begin{array}{l}0.74 \\
0.18\end{array}$ & $\begin{array}{l}1.18(0.54-2.55) \\
0.85(0.46-1.57)\end{array}$ & $\begin{array}{l}0.68 \\
0.59\end{array}$ \\
\hline $\begin{array}{l}\text { Abbreviations: } \mathrm{C} \\
\text { users; } \mathrm{H}=\text { weakl) } \\
\text { survival; PFS }=\mathrm{pr} \\
\text { a Multicovariate } \\
\text { status as the stra } \\
\text { lymphatic/vascul } \\
\text { DSS. }\end{array}$ & $\begin{array}{l}=\text { confidence interval; } \\
\text { ipophilic and hydroph } \\
\text { gression-free survival. } \\
\text { odels included radiati } \\
\text { fication factors and ad } \\
\text { invasion, nuclear grad }\end{array}$ & $\begin{array}{l}\text { SS = disease } \\
\text { lic statin use } \\
\text { on therapy, } \\
\text { usted for lyn } \\
\text { and surger }\end{array}$ & $\begin{array}{l}\text { specific survival; } L=l i \\
\text { s; } N=\text { non-statin users } \\
\text { ormonal receptor stat } \\
\text { phatic/vascular invasio } \\
\text { within } 1 \text { year (Yes vs } N\end{array}$ & $\begin{array}{l}\text { ophilic statin } \\
\text { OS = overall } \\
\text { is and HER2 } \\
\text { for PFS and } \\
\text { p) for OS and }\end{array}$ \\
\hline
\end{tabular}

Table 4 shows the final multicovariate Cox model for PFS, OS, and DSS, comparing the L-statin $v s$ non-statin group, as well as the $\mathrm{H}$-statin $v s$ non-statin group. This multicovariate analysis included HR status and HER2 status as the stratification factors and was adjusted for lymphatic/vascular invasion for PFS and lymphatic/ vascular invasion, nuclear grade, and surgery within 1 year for OS and DSS. Compared with the non-statin group, the $\mathrm{H}$-statin group was associated with a lower risk of disease progression or death $(\mathrm{HR}(95 \% \mathrm{CI})=0.49(0.28-0.84), P<0.01)$. The $\mathrm{H}$-statin group had a trend towards lower HRs for OS and DSS compared with the non-statin group; however, $P$-values were 0.49 and 0.59 , respectively. Lack of either lymphatic or vascular invasion was significantly associated with better PFS compared with the presence of both lymphatic and vascular invasion (HR (95\% CI) $=0.59(0.47-0.75), P=<0.01)$. The Kaplan-Meier curves for PFS of the three groups are shown in Figure 1.

Effects of different statins were further investigated in our subanalysis, in which we compared atorvastatin users, simvastatin users, and non-statin users. Table 5 shows the results of the multicovariate analysis on the primary outcome. Compared with non-statin user, atorvastatin use was associated with statistically significant advantages for PFS (HR (95\% CI) $=0.48(0.25-0.95)$, $P=0.03$ ). The observed PFS benefit was similar to that in the analysis comparing $\mathrm{H}$-statin users vs non-statin users, because $66 \%$ of patients in the $\mathrm{H}$-statin group used atorvastatin. In a similar vein, $93 \%$ of patients in L-statin group used simvastatin. Therefore, the observed HRs for L-statin vs non-statin and H-statin vs nonstatin were similar to those for simvastatin $v s$ non-statin and atorvastatin $v s$ non-statin. As the Kaplan-Meier curve for this subanalysis is practically the same as Figure $1(\mathrm{H}$-statin and L-statin vs non-statin), it is not included in this report.

\section{DISCUSSION}

$\mathrm{H}$-statins, not L-statins, were associated with significantly improved PFS in our cohort, which supported our hypothesis that

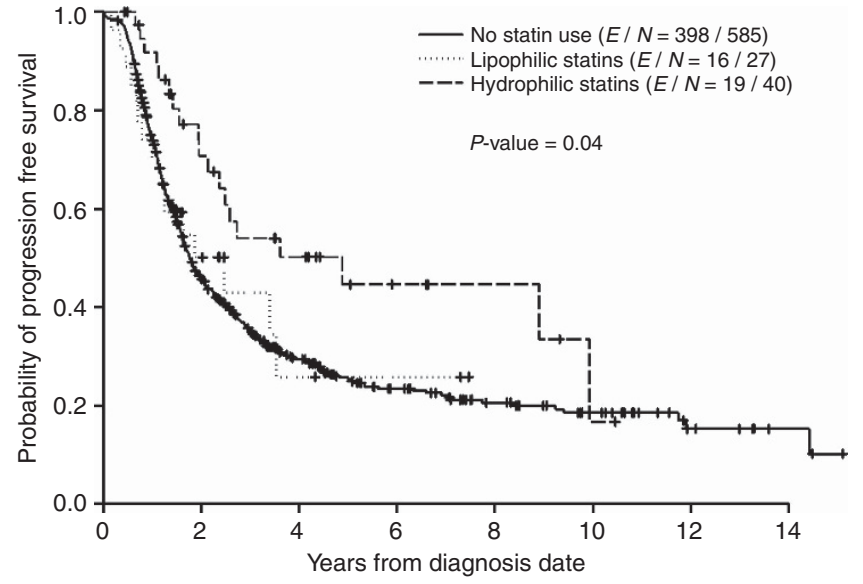

Figure 1. Kaplan-Meier curve for PFS comparing $\mathrm{H}$-statin users, L-statin users, and non-statin users.

\begin{tabular}{|c|c|c|}
\hline & \multicolumn{2}{|c|}{ Multicovariate cox model } \\
\hline Covariates & $\mathrm{HR}(95 \% \mathrm{Cl})$ & $\boldsymbol{P}$-value \\
\hline \multicolumn{3}{|l|}{ PFS } \\
\hline Statin Atorva vs N & $0.48(0.25-0.95)$ & 0.03 \\
\hline Simva vs $\mathrm{N}$ & $0.72(0.38-1.36)$ & 0.30 \\
\hline \multicolumn{3}{|l|}{ OS } \\
\hline Statin Atorva vs N & $1.00(0.49-2.05)$ & 0.99 \\
\hline Simva vs $\mathrm{N}$ & $1.38(0.67-2.85)$ & 0.38 \\
\hline \multicolumn{3}{|l|}{ DSS } \\
\hline Statin Atorva vs N & $1.05(0.51-2.17)$ & 0.89 \\
\hline Simva vs $\mathrm{N}$ & $1.07(0.47-2.46)$ & 0.87 \\
\hline \multicolumn{3}{|c|}{$\begin{array}{l}\text { Abbreviations: } \mathrm{Cl}=\text { confidence interval; } D S S=\text { disease-specific survival; } N=\text { non-statir } \\
\text { users; } O S=\text { overall survival, } P F S=\text { progression-free survival. }\end{array}$} \\
\hline
\end{tabular}

certain statins reduce the recurrence potential of primary IBC. However, the results were not consistent with our thought that lipophilic statins would be more effective.

The inverse association between $\mathrm{H}$-statin use and recurrence risk observed in our study is in agreement with other reports showing that statin use is associated with improved PFS times (Kwan et al, 2008; Ahern et al, 2011). Furthermore, our study is the first to provide clinical evidence potentially linking $\mathrm{H}$-statin use to significantly improved PFS in primary IBC. H-statin users, however, had marginally improved OS and DSS compared with non-statin users. Failure to demonstrate statistically significant results in OS and DSS may have been due to a small cohort size, and/or because statins in general might not be effective in controlling or stopping progression once the disease becomes metastatic. The lack of association of L-statin use with improvement in PFS, DSS, and OS is not consistent with some studies that have shown lipophilic statins being associated with improved outcomes.

In light of improved PFS in H-statin users but not in L-statin users, one can speculate that certain types of statin may block any step involved in initiation of metastasis, including invasion, extravasation, epithelial-mesenchymal transition and angiogenesis, and may block steps involving cancer stem cells. One recent 
prospective laboratory study, which supports our observational findings is a non-randomised, phase II clinical trial assessing effects of atorvastatin on breast cancer in the neoadjuvant setting, conducted by Bjarnadottir et al (2013). Their study showed that 2 weeks of high-dose atorvastatin reduced the proliferation index of $\mathrm{Ki}-67$ in tumour cells positive for HMG-CoA reductase. It is hypothesised that hydrophilic statins only inhibit HMG-CoA reductase within the liver and, as part of positive feedback, promote upregulation of HMG-CoA reductase in extrahepatic tissue, including the breast. Lipophilic statins such as simvastatin, on the other hand, inhibits both intrahepatic and extrahepatic HMG-CoA reductase activity and thus might be associated with decrease incidence or recurrence (Duncan et al, 2005). In our study, simvastatin, a highly lipophilic statin, demonstrated less protective effects than atorvastatin, a lesser lipophilic statin. Pharmacologically speaking, atorvastatin is much more potent than simvastatin, with stronger binding capacity to HMG-CoA inhibitors (da Costa et al, 2012), which may explain the better outcomes in our H-statin group, in which the majority of patients were using atorvastatin.

We acknowledge that controversy may arise regarding the classification of statins used in this study. We are aware that, depending on the investigators, the hydrophobicity of certain statins can be classified differently. Atorvastatin is often referred to as lipophilic statin, especially when statins are classified based on tissue selectivity and Log $\mathrm{D}$ classification at $\mathrm{pH}=7.4$ (McTaggart et al, 2001; White, 2002). When statins are classified based on an octal:water log partition coefficient (Log P), which was adopted by Ahern et al, 2011, the relative lipophobicity of statins at $\mathrm{pH}=7.4$ is indeed a 'spectrum' and not as clear cut as 'hydrophilic' $v s$ 'lipophilic'. Joshi et al (1999) showed the relative lipophobicity of different statins with the most hydrophilic pravastatin as the reference drug (rating of 1), followed by lovastatin (rating of 71), atorvastatin (76), fluvastatin (105), cerivastatin (219) and simvastatin (310) (Joshi et al, 1999). The study by Ahern et al (2011) (JNCI 2011) is one of the most recent works examining association between statin use and breast cancer recurrence risk, which showed promising results with a large cohort of 18769 women with breast cancer. Our initial hypothesis was that use of a statin, especially a lipophilic statin such as simvastatin, may also improve clinical outcomes in an IBC population. To evaluate the outcomes in a setting that paralleled the design of Ahern et al (2011) study, the largest breast cancer cohort study addressing statin use to date, we used their classification. We are not in a position to disprove their classification. Alterations to their classification system in the future may necessitate reevaluation of our data.

A caveat to our findings is the potential for confounding by indications for statin use. Interestingly, one study showed that hypercholesterolaemia lowers the risk of metastasis in breast cancer, and it was hypothesised that high-serum cholesterol levels impair angiogenesis by suppressing tumoral and endothelial basic fibroblast growth factor and vascular endothelial growth factor (Ozdemir et al, 2004). That study by Ozdemir et al (2004), however, was not adjusted for any medication uses other than chemotherapy and hormonal therapy. None of the women studied were on statin before, during and after breast cancer treatment. Even in light of potential confounding factors, such as those described above, statins are known to have pleiotropic effects, including impeding tumour cell growth and antioxidant properties. Furthermore, if the formation of atherosclerotic vessels in hypercholesterolaemia inhibits recurrence and metastasis, statins, which stabilise endothelial function through their anti-atherosclerotic function, would be expected to favour recurrence or metastasis via the hematogenous route. However, our observations were discordant with this reasoning.

This study is limited by its observational nature. The treatment of statins was not randomly assigned but was determined at the initial evaluation of primary IBC. Medication compliance could not be confirmed and underreporting of statin use could be a potential source of error. Also the duration of statin use could not be assessed. Besides the indication for statin use, other possible confounding factors include other medications not included in this study, which may influence relapse, as well as lifestyle differences such as diet, exercise, alcohol and tobacco intake, socioeconomic status, and educational levels. Those who took statins may represent a population with better access to health care, a more health-conscious lifestyle and higher educational levels, thus potentially favouring a longer PFS time.

One of the strengths of the study is that the MD Anderson Breast Cancer Management System is prospectively and systematically maintained and survival information is updated every 9 months. Furthermore, in this single-institution study, the therapy given was more homogeneous than it might have been at multiple centres. The majority of patients included in our study (99.3\%) received neoadjuvant chemotherapy, which is the standard of care for primary IBC. Although most published studies have evaluated all types of breast cancer collectively, we focused on primary IBC, resulting in a study cohort that is more biologically homogeneous and thus provides more useful clinical information. Interestingly, unlike recent publications on non-IBC breast cancer populations, beta-blocker use was not associated with better outcomes in our cohort in the univariate analysis (Barron et al, 2011; Melhem-Bertrandt et al, 2011). Furthermore, ACEI/ARB use and bisphosphonate use were not found to be independent prognostic factors when analysed in the multivariable fashion, although some studies suggest these medications may have survival benefits in breast cancer (Gnant et al, 2009; Eidtmann et al, 2010; Chae et al, 2011). We did not exclude adjuvant use of drugs other than statins; this might explain the discrepancy between our study and others showing efficacy of drugs other than statins on clinical outcomes in breast cancer.

Owing to the aggressive nature of primary IBC and its high early-relapse rate, discovery of more effective therapies for this unique population is desired. Thus, it is crucial to design extensive preclinical studies to elucidate the molecular and biological mechanisms of IBC and its tumorigenesis and metastasis. Data presented in our study are of great interest and are also hypothesis generating. Thus, prospective evaluation of statins in IBC, including double-blinded prospective randomised controlled studies, is warranted to validate these preliminary results.

\section{ACKNOWLEDGEMENTS}

We thank Limin Hsu, Department of Breast Medical Oncology, The University of Texas MD Anderson Cancer Center, for his assistance in data management and data clarification; Jie Willey, Department of Breast Medical Oncology, the University of Texas MD Anderson Cancer Center, for assistance with protocol issues; and Sunita Patterson, Department of Scientific Publications, The University of Texas MD Anderson Cancer Center, for editorial assistance. This work was supported by National Institute of Health grants [R01 CA123318] to Naoto Ueno and MD Anderson's Cancer Center Support Grant [CA016672], the Morgan Welch Inflammatory Breast Cancer Research Program and Clinic, and the State of Texas Rare and Aggressive Breast Cancer Research Program Grant to Naoto Ueno.

\section{CONFLICT OF INTEREST}

The authors declare no conflict of interest. 


\section{REFERENCES}

Ahern TP, Pedersen L, Tarp M, Cronin-Fenton DP, Garne JP, Silliman RA, Sørensen HT, Lash TL (2011) Statin prescriptions and breast cancer recurrence risk: a Danish nationwide prospective cohort study. J Natl Cancer Inst 103(19): 1461-1468.

Barron TI, Connolly RM, Sharp L, Bennett K, Visvanathan K (2011) Beta blockers and breast cancer mortality: a population-based study. J Clin Oncol 29(19): 3635-2644.

Bjarnadottir O, Romero Q, Bendahl PO, Jirström K, Rydén L, Loman N, Uhlén M, Johannesson H, Rose C, Grabau D, Borgquist S (2013) Targeting HMG-CoA reductase with statins in a window-of-opportunity breast cancer trial. Breast Cancer Res Treat 138(2): 499-508.

Bonovas S, Filioussi K, Tsavaris N, Sitaras NM (2005) Use of statins and breast cancer: a meta-analysis of seven randomized clinical trials and nine observational studies. J Clin Oncol 23(34): 8606-8612.

Cauley JA, McTiernan A, Rodabough RJ (2006) Statin use and breast cancer: prospective results from the Women's Health Initiative. J Natl Cancer Inst 17 98(10): 700-707.

Chae YK, Valsecchi ME, Kim J, Bianchi AL, Khemasuwan D, Desai A, Tester W (2011) Reduced risk of breast cancer recurrence in patients using ACE inhibitors, ARBs, and/or statins. Cancer Invest 29: 585-593.

Clendening JW, Pandyra A, Boutros PC (2010) Dysregulation of the mevalonate pathway promotes transformation. PNAS 107(34): 15051-15056.

Cox DR (1958) Regression models and life tables (with discussion). J Roy Statist Soc B 34: 187-220.

Cristofanilli M, Valero V, Buzdar AU, Kau SW, Broglio KR, Gonzalez-Angulo AM, Sneige N, Islam R, Ueno NT, Buchholz TA, Singletary SE, Hortobagyi GN (2007) Inflammatory breast cancer (IBC) and patterns of recurrence: understanding the biology of a unique disease. Cancer 110(7): 1436-1444.

Dawood S, Merajver SD, Viens P, Vermeulen PB, Swain SM, Buchholz TA, Dirix LY, Levine PH, Lucci A, Krishnamurthy S, Robertson FM, Woodward WA, Yang WT, Ueno NT, Cristofanilli M (2011) International expert panel on inflammatory breast cancer; consensus statement for standardized diagnosis and treatment. Ann Oncol 22(3): 515-523.

da Costa RF, Freire VN, Bezerra EM, Cavada BS, Caetano EW, de Lima Filho JL, Albuquerque EL (2012) Explaining statin inhibition effectiveness of HMG-CoA reductase by quantum biochemistry computations Phys. Chem Chem Phys 14: 1389-1398.

Dunkan RE, El-Sohemy A, Archer MC (2004) Mevalonate promotes the growth of tumors derived from human cancer cells in vivo and stimulates proliferation in vitro with enhanced cyclin-dependent kinase- 2 activity. J Biol Chem 6 279(32): 33079-33084.

Dunkan ER, El-Sohemy A, Archer MC (2005) Statins and cancer development. Cancer Epidemiol Biomarkers Prev 14(8): 1897-1898.

Eidtmann H, Boer R, Bundred N (2010) Efficacy of zoledronic acid in postmenopausal women with early breast cancer receiving adjuvant letrozole: 36-month results of the ZO-FAST study. Ann Oncol 21: 2188-2194.

Gonzalez-Angulo AM, Hennessy BT, Broglio K, Meric-Bernstam F, Cristofanilli M, Giordano SH, Buchholz TA, Sahin A, Singletary SE, Buzdar AU, Hortobágyi GN (2007) Trends for inflammatory breast cancer: is survival improving? Oncologist 12(8): 904-912.

Ghosh-Choudhury N, Mandal CC, Ghosh-Choudhury N, Ghosh-Choudhury G (2010) Simvastatin induces depression of PTEN expression via NFkappaB to inhibit breast cancer growth. Cell Signal 22(5): 749-758.

Gnant M, Mlineritsch B, Schippinger W, Luschin-Ebengreuth G, Pöstlberger S, Menzel C, Jakesz R, Seifert M, Hubalek M, Bjelic-Radisic V, Samonigg H, Tausch C, Eidtmann H, Steger G, Kwasny W, Dubsky P, Fridrik M, Fitzal F, Stierer M, Rücklinger E, Greil R. ABCSG-12 Trial InvestigatorsMarth C (2009) Endocrine therapy plus zoledronic acid in premenopausal breast cancer. N Engl J Med 360(7): 679-691.
Joshi HN, Fakes MG, Serajuddin ATM (1999) Differentiation of 3-hydroxyl3-methylglutaryl-coenzyme A reductase inhibityors by their relative lipophilicity. Pharm Pharmacol Commun 5: 269-271.

Kaplan EL, Meier P (1958) Nonparametric estimation from incomplete observations. J Amer Statist Assoc 53: 457-481.

Kenneth HW, William AF, Devesa SS, Young HA, Levine PH (2005) Trends in inflammatory breast carcinoma incidence and survival: the surveillance, epidemiology, and end results program at the National Cancer Institute. J Natl Cancer Inst 97(13): 966-975.

Kubota T, Fujisaki K, Itoh Y, Yano T, Sendo T, Oishi R (2004) Apoptotic injury in cultured human hepatocytes induced by HMG-CoA reductase inhibitors. Biochem Pharmacol 67(12): 2175-2186.

Konstantinopoulos PA, Karamouzis MV, Papavassiliou AG (2007) Posttranslational modifications and regulation of the RAS superfamily of GTPases as anticancer targets. Nat Rev Drug Discovery 6(7): 541-555.

Kwan ML, Habel LA, Flick ED, Quesenberry CP, Caan B (2008) Postdiagnosis statin use and breast cancer recurrence in a prospective cohort study of early stage breast cancer survivors. Breast Cancer Res Treat 109(3): 573-579.

Lefer DJ (2002) Statins as potent anti-inflammatory drugs. Circulation 106(16): 2041-2042.

Ma J, Sehgal NL, Ayanian JZ, Stafford RS (2005) National trends in statin use by coronary heart disease risk category. PLoS Med 2(5): el23.

Mandal CC, Ghosh-Choudhury N, Yoneda T, Choudhury GG, GhoshChoudhury N (2011) Simvastatin prevents skeletal metastasis of breast cancer by an antagonistic interplay between $\mathrm{p} 53$ and CD44. J Biol Chem 286(13): 11314-11327.

McTaggart F, Buckett L, Davidson R, Holdgate G, McCormick A, Schneck D, Smith G, Warwick M (2001) Preclinical and clinical pharmacology of Rosuvastatin, a new 3-hydroxy-3-methylglutaryl coenzyme A reductase inhibitor. Am J Cardiol Mar 87(5A): 28B-32B.

Melhem-Bertrandt A, Chavez-Macgregor M, Lei X, Brown EN, Lee RT, Meric-Bernstam F, Sood AK, Conzen SD, Hortobagyi GN, Gonzalez-Angulo AM (2011) Beta-blocker use is associated with improved relapse-free survival in patients with triple-negative breast cancer. J Clin Oncol 29(19): 2645-2652.

National Center for Health Statistics (US) (2010) Health, united states (2010) with special feature on death and dying. U.S. http://www.cdc.gov/nchs/ data/hus/hus10.pdf.

Nielsen SF, Nordestgaard BG, Bojesen SE (2012) Statin use and reduced cancer-related mortality. N Eng J Med 367: 1792-1802.

Ozdemir BH, Akcali Z, Haberal M (2004) Hypercholesterolemia impairs angiogenesis in patients with breast carcinoma and, therefore, lowers the risk of metastases. Am J Clin Pathol 122(5): 696-703.

Prowell TM, Stearns V, Trock B (2006) Lipophilic statins merit additional study for breast cancer chemoprevention. J Clin Oncol 24(13): 2128-2129.

Rao S, Lowe M, Herliczek TW, Keyomarsi K (1998) Lovastatin mediated G1 arrest in normal and tumor breast cells is through inhibition of CDK2 activity and redistribution of $\mathrm{p} 21$ and $\mathrm{p} 27$, independent of $\mathrm{p} 53$. Oncogene 17(18): 2393-2402.

Sacks FM, Pfeffer MA, Moye LA, Rouleau JL, Rutherford JD, Cole TG, Brown L, Warnica JW, Arnold JM, Wun CC, Davis BR, Braunwald E (1996) The effect of pravastatin on coronary events after myocardial infarction in patients with average cholesterol levels. N Eng J Med 335(14): 1001-1009.

Shibata MA, Ito Y, Morimoto J, Otsuki Y (2004) Lovastatin inhibits tumor growth and lung metastasis in mouse mammary cardinoma model: p53-inependent mitochondrial-mediated apoptotic mechanism. Carcinogenesis 25(10): 1887-1898.

White CM (2002) A review of the pharmacologic and pharmacokinetic aspects of rosuvastatin. J Clin Pharmacol 42(9): 963-970.

This work is published under the standard license to publish agreement. After 12 months the work will become freely available and the license terms will switch to a Creative Commons AttributionNonCommercial-Share Alike 3.0 Unported License.

Supplementary Information accompanies this paper on British Journal of Cancer website (http://www.nature.com/bjc) 